\title{
THERMAL CONDUCTIVITY OF NATURAL MATERIALS USED FOR THERMAL INSULATION
}

\author{
Pavel Neuberger, Pavel Kic \\ Czech University of Life Sciences Prague \\ neuberger@tf.czu.cz, kic@tf.czu.cz
}

\begin{abstract}
The possibility to determine the thermal conductivity of construction materials outside the laboratory conditions is useful for professional practice mainly for control and inspection activities on real existing buildings. This paper describes the method and results of measurements focused on different natural thermal insulations based on agricultural products as strawboard panel Solomit and thermal insulating material from hemp, which are used mainly for improvement of the thermal properties of buildings. The measuring principle was based on the dynamic unsteady method. The measurement consists in the analysis of a thermal response of the tested material to heat flux pulses. Thermal conductivity of Solomit straw board panels with the longitudinal alignment of stalks to the direction of heat flux was $0.089 \mathrm{~W} \cdot \mathrm{m} \cdot \mathrm{K}^{-1}$ and with the transversal alignment of stalks $0.066 \mathrm{~W} \cdot \mathrm{m} \cdot \mathrm{K}^{-1}$. Results of the measurement confirmed that the thermal conductivity of the straw boards depends on the orientation of the stalk material. If the heat flux is directed in a direction perpendicular to the blades the thermal conductivity is lower than that in the direction along the stalks. The thermal conductivity of the natural insulation material manufactured from hemp was from 0.041 to $0.046 \mathrm{~W} \cdot \mathrm{m} \cdot \mathrm{K}^{-1}$. Crushing of the stalk structure before the production of building materials of vegetable origin enables the subsequent production of panels with constant thermal insulation properties. By deformation of the thermal insulating material not only its density is changed, but also the thermal conductivity. Solomit straw board panels used during sixty years historically demonstrated the reasonable use of this material in lightweight constructions for agriculture and other purposes.
\end{abstract}

Keywords: dynamic measurement, hemp insulation, strawboard panel Solomit, thermal properties.

\section{Introduction}

Natural materials are used in the construction of buildings by human societies for thousands of years. People used mainly locally available materials (wood, stones etc.). Construction benefited from development of agriculture initiated and supported the use of agricultural products, mainly from plant production, also for constructions. In addition to traditional materials have been utilized straw, husks, stalks and other plant materials.

The Industrial Revolution and the migration of population from villages to cities began the transition to the use of building materials produced by industrial methods.

Nevertheless, some building materials of vegetal origin remain in the construction industry. New building materials, environmentally friendly, the production of which involves the use of modern technology, are becoming more and more popular. For example, in Czechoslovakia at the time of transition to large-scale farming and modern agricultural technologies $\left(50^{\text {th }}-60^{\text {th }}\right.$ years $)$ building industry frequently used strawboards made from natural materials. For their labelling the historical term Solomit has been used. This term is historically denoted to insulation materials made from straw.

Mobile technology produced in Czechoslovakia for Solomit strawboard production should be used by farmers directly in agricultural farms. The technological line for production of Solomit strawboard panels was based on two machines: the first one was the press machine LS-140 for production of strawboard panels and the second machine AS-50 for the production of staples [1].

Mustard and rape straw was used predominantly to produce strawboard panels Solomit. This was pressed at high pressure and subsequently stitched with galvanized wire. Literature [2] presents the value of the thermal conductivity of the plates in the range $\lambda=0.081 \div 0.151 \mathrm{~W} \cdot \mathrm{m} \cdot \mathrm{K}^{-1}$. Strawboard panels were presented as non-flammable. They have also been used as sound insulation. According to practical experience, e.g., in the construction of unheated barns for pigs double strawboard panels Solomit for heat balance improvement were advised to use; for construction of lightweight plaster buildings simple strawboard panels Solomit were recommended, but covered by plaster on both sides [3].

Similar construction elements are produced also nowadays, e.g., by the Australian company SOLOMIT STRAWBOARD PTY. LTD (Dandenong, Victoria, Australia). This company manufactures strawboard panels for constructions of acoustic ceilings. The raw material for their production is wheat or oat straw. Plates are produced with a thickness $25 \mathrm{~mm}$ and $50 \mathrm{~mm}$, a length 
$1,200 \div 4,000 \mathrm{~mm}$ and stock width $1,200 \div 1,220 \mathrm{~mm}$ or special widths 820 to $1,200 \mathrm{~mm}$ ). The density of the material for acoustic ceilings made from straw is $161 \mathrm{~kg} \cdot \mathrm{m}^{-3}$ and the thermal conductivity of $\lambda=0.057 \mathrm{~W} \cdot \mathrm{m} \cdot \mathrm{K}^{-1}$. The company produces fence panels from bushes. The panel thickness is 25 or $50 \mathrm{~mm}$. One standard field fence dimensions are $1,800 \times 1,800(1,500) \mathrm{mm}$ and the weight of a standard panel is $65 \mathrm{~kg}$. It is assumed for lifespan of 20 to 30 years.

Solomit as a thermal insulation is mentioned in literature [4]. The thermal conductivity of Solomit is $\lambda=0.041 \mathrm{~W} \cdot \mathrm{m} \cdot \mathrm{K}^{-1}$ at a density of $213 \mathrm{~kg} \cdot \mathrm{m}^{-3}$. Architectural use of Solomit boards produced in Australia is described in literature [5]. There are also mentioned positive and suitable thermal and acoustic properties of Solomit strawboard plates.

There were tested different natural materials used as a thermal insulation, presented, e.g., in the literature [6].

An example of a modern natural thermal insulating material is Thermo HANF® Premium Plus produced from hemp by the company Thermo Natur GmbH \& Co. KG (Nördlingen, Germany). As a binder of hemp particles corn starch is used, among other products this company uses also artificial fiber based on polyester.

The article evaluates the thermal conductivity of strawboard plates Solomit produced in the $60^{\text {th }}$ of the last century in Czechoslovakia. The sample was obtained during the recent demolition of a farm house. A dynamic method of measurement has been used to determine the thermal conductivity. The thermo-insulating properties of the material Thermo HANF® Premium Plus were verified by the same experimental method.

\section{Materials and methods}

The results presented in this paper are based on the measurement by the portable instrument Isomet 2104 (Applied Precision, Ltd., Bratislava, Slovakia). This instrument is controlled by a microprocessor, to which the manufacturer supplies an exchangeable needle and surface sensors of various ranges. The calibration constants are stored in the sensor memory.

This instrument measures the thermal conductivity of compact and loose materials in a range of $0.015 \div 2 \mathrm{~W} \cdot \mathrm{m}^{-1} \cdot \mathrm{K}^{-1}$. For the thermal conductivity in the range $0.015 \div 0.050 \mathrm{~W} \cdot \mathrm{m}^{-1} \cdot \mathrm{K}^{-1}$ is permissible measurement error $5 \%$ of reading $+0.003 \mathrm{~W} \cdot \mathrm{m}^{-1} \cdot \mathrm{K}^{-1}$. There is also measured the temperature (measurement error of $\pm 1^{\circ} \mathrm{C}$ ) and specific heat capacity of materials (the measurement error of $15 \%$ of the value of $+1000 \mathrm{~J} \cdot \mathrm{m}^{-3} \cdot \mathrm{K}^{-1}$ ). The measured values can be stored in the internal memory of the instrument. The content of memory is accessible via display. Data can be transferred via RS-232 interface to a PC. The instrument can be powered from AC or battery.

To determine the thermal conductivity of the material the unsteady method is used. This compared to stationary methods significantly reduces the time of the measurement. The device analyses the time dependence of thermal responses to impulses of the heat flux supplied to the material. The heat flux creates scattered electric output from the resistor located in the sensor. The sensor has a thermally conductive connection with the analyzed material. Temperature resistance is sensed by a semiconductor sensor.

Temperature variation as a function of time is tested in discrete points. The obtained points are interleaved by regression polynomials using the method "least squares". The coefficients of the regression polynomials are used to calculate the thermo-physical parameters using analytical formulas.

Air temperatures and relative humidity were measured by the sensor FHA 646-21 including the temperature sensor NTC type $\mathrm{N}$ with operative range from -30 to $+100{ }^{\circ} \mathrm{C}$ with accuracy $\pm 0.1{ }^{\circ} \mathrm{C}$, and air humidity by the capacitive sensor with operative range from 5 to $98 \%$ with accuracy $\pm 2 \%$ connected to the measuring instrument ALMEMO 2590-9 (Ahlborn GmbH, Germany).

For the indirect measurement of material moisture the capacitive sensor FH A696-MF was used with the operative range of mineral construction materials from 0 to $20 \%$ with accuracy $0.1 \%$. The sensor was connected to the data logger ALMEMO 2690-8 (Ahlborn GmbH, Germany).

Material 1 (Fig. 1) is strawboard panel Solomit of the thickness $50 \mathrm{~mm}$ obtained from the reconstructed farm house after sixty years of use. The raw material for the production of strawboard panel Solomit was rape straw. Two installations of the needle sensor into the material were tested. The 
first arrangement (A) with the longitudinal alignment of stalks to the direction of the heat flux - the needle sensor was installed into the material across the direction of the stalks and arrangement B with the transversal alignment of stalks to the direction of the heat flux - the needle sensor was installed into the material in the direction of the stalks.

Material 2 (Fig. 2) is Thermo HANF® Premium Plus, which is a natural insulation material manufactured from hemp by the company Thermo Natur GmbH \& Co. KG (Nördlingen, Germany). As a binder of hemp particles corn-starch is used. This material can be used as good quality insulation.

The original plate having the thickness of $80 \mathrm{~mm}$ was pressed to 60 and $50 \mathrm{~mm}$, thereby changing the density of the material (sample weight was retained). Two samples of this material (labelled A and B) were available for this measurement. The material was tested with the longitudinal alignment of stalks to the direction of the heat flux - the needle sensor was installed into the material across the direction of the stalks and also with the transversal alignment of stalks to the direction of the heat flux - the needle sensor was installed into the material in the direction of the stalks.

The thermal conductivity was determined by the needle probe connected to the instrument Isomet 2104. The results of the measurement were processed by Excel software and important parameters were verified by statistical software Statistica 12 (ANOVA and TUKEY HSD Test).

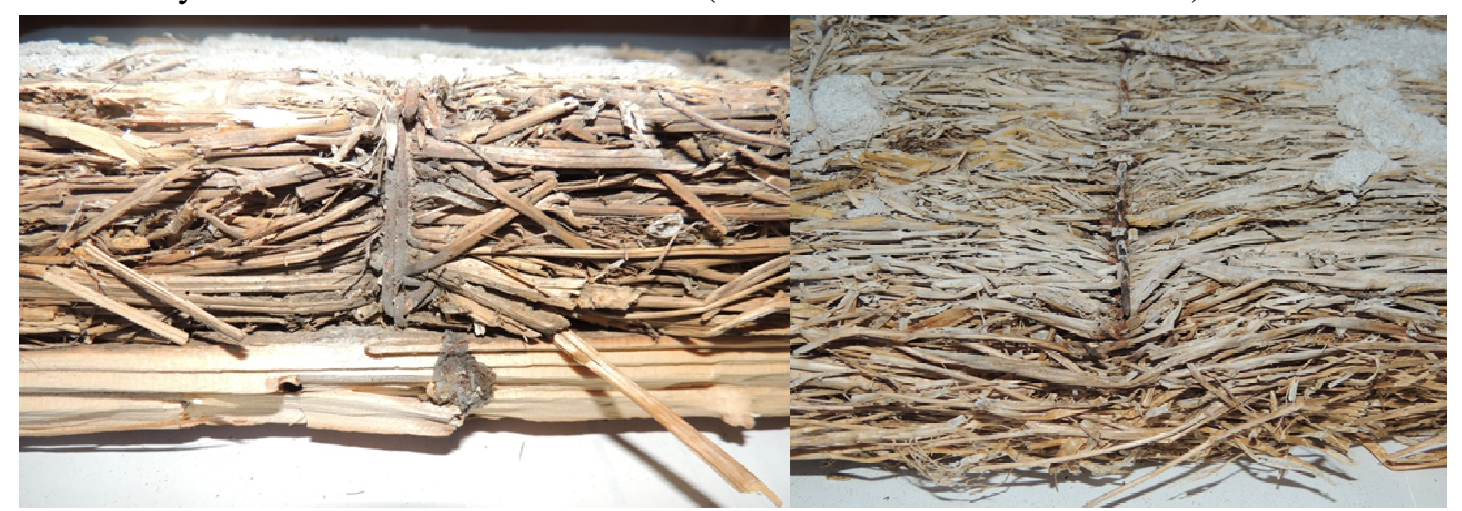

Fig. 1. Strawboard panel Solomit: left - cross-section of material attached to wooden structure; right - material stitched with steel staples

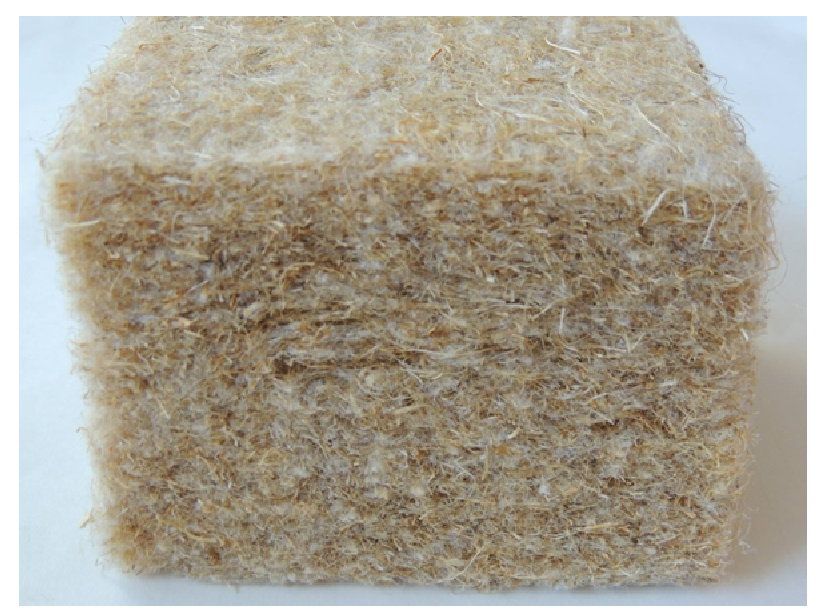

Fig. 2. Natural insulation material Thermo HANF® Premium Plus

\section{Results and discussion}

The results of the measurement of the thermal conductivity of Solomit plate of $50 \mathrm{~mm}$ thickness are presented in Table 1. Table 1 summarizes the basic measurement data in the form of basic statistical quantities for the measurement with the longitudinal alignment of stalks to the direction of the heat flux - the needle sensor was installed into the material across the direction of the stalks (column A) and with the transversal alignment of stalks to the direction of the heat flux - the needle sensor was installed into the material in the direction of the stalks (column B). 
There are presented measurement conditions: the average temperature of the material sample at the beginning of the measurement $t_{m}$, the density of the material sample $\rho_{m}$, the average moisture of the material $w_{m}$, the average air temperature at the beginning of the measurement $t_{e}$ and the results of the measurement of the thermal conductivity $\lambda_{m}$, which are compared with the value $\lambda$ declared by the manufacturer. The data are the mean values \pm SD. Different letters $(a, b)$ in the superscript are the sign of high significant differences (ANOVA; Tukey HSD Test; $p \leq 0.05$ ).

Measurement of thermal conductivity of strawboard panel Solomit

Table 1

\begin{tabular}{|c|c|c|c|}
\hline Parameter & Units & $\begin{array}{c}\text { Measurement A } \\
\text { longitudinal } \\
\text { alignment of } \\
\text { stalks }\end{array}$ & $\begin{array}{c}\text { Measurement B } \\
\text { transversal } \\
\text { alignment of } \\
\text { stalks }\end{array}$ \\
\hline$\rho_{m}$ & $\mathrm{~kg} \cdot \mathrm{m}^{-3}$ & 140 & 140 \\
\hline$t_{m} \pm S D$ & ${ }^{\circ} \mathrm{C}$ & $23.4 \pm 1.29$ & $24.7 \pm 1.29$ \\
\hline$w_{m} \pm S D$ & $\%$ & $2.71 \pm 0.25^{\mathrm{a}}$ & $2.70 \pm 0.22^{\mathrm{a}}$ \\
\hline$t_{e} \pm S D$ & ${ }^{\circ} \mathrm{C}$ & $24.1 \pm 0.76$ & $25.7 \pm 0.165$ \\
\hline$\lambda_{m} \pm S D$ & $\mathrm{~W} \cdot \mathrm{m}^{-1} \cdot \mathrm{K}^{-1}$ & $0.089 \pm 0.009^{\mathrm{a}}$ & $0.066 \pm 0.009^{\mathrm{b}}$ \\
\hline$\lambda$ & $\mathrm{W} \cdot \mathrm{m}^{-1} \cdot \mathrm{K}^{-1}$ & \multicolumn{2}{|c|}{$0.081 \div 0.151$} \\
\hline
\end{tabular}

A comparison of thermal properties of the material (plate Solomit) listed in Table 1 shows that better thermal properties of the material is achieved in the case if the heat flux is directed transversally through the hollow blades (when the measurement needle probe is inserted in the direction of the blades). This can be explained by the principle of serial shifting of partial thermal resistances (plant material - air - plant material etc.). A similar model is used to justify the conduction of heat in aerated soil [7]. In the production of thermal insulation elements from natural stalk materials, it must therefore be ensured that the stalks are lying across the expected heat flux. During production, the described technological process must be exactly respected.

The results of the measurement of the thermal conductivity of the insulation material TERMO HANF® Premium Plus are presented in Table 2. Table 2 summarizes the basic measurement data in the form of basic statistical quantities for the measurement of the tested material. There were not different results of the measured parameters of both sensor arrangements, therefore the results are presented in Table 2. There are compared two tested samples of the same material but with slightly different properties (sample A and sample B).

In Table 2 the measurement conditions are presented: thickness of the material $t$, density of material sample $\rho_{m}$, average moisture of the material $w_{m}$, average temperature of the material sample at the beginning of the measurement $t_{m}$, average air temperature at the beginning of the measurement $t_{e}$ and the results of the measurement of the thermal conductivity $\lambda_{m}$, which are compared with the value $\lambda$ declared by the manufacturer. The data are the mean values $\pm S D$. The data are the mean values $\pm S D$. Different letters (a, b, c, d, e, f) in the superscript are the sign of high significant differences (ANOVA; Tukey HSD Test; $p \leq 0.05)$.

In the production of the thermal insulation material Thermo HANF® Premium Plus the internal structure of the material of vegetable origin before the production of the insulating panel is destroyed and crushed. Influence of straw arrangement in this case does not occur, which is confirmed by the same results in Table 2 on both samples A and B. Suitable material structure affects the insulating properties of the final product (insulating panel). It is created comprised of vegetable particles together with not closed air chambers. Crushing of vegetable material and respecting the technological instructions is a prerequisite for the production of thermal insulation panel with stable thermal insulating properties.

By deformation of the thermal insulating material not only its density is changed, but also the thermal conductivity. It is illustrated by the thermal conductivity values shown in Table 2 . To achieve the parameters of thermal properties determined by the manufacturer, the mechanical deformation of insulation materials must be prevented. 
Table 2

Measurement of thermal conductivity of insulation material TERMO HANF® Premium Plus

\begin{tabular}{|c|c|c|c|c|c|c|c|}
\hline Parameter & Units & \multicolumn{3}{|c|}{ Measurement arrangement A } & \multicolumn{3}{|c|}{ Measurement arrangement B } \\
\hline $\mathrm{t}$ & $\mathrm{mm}$ & 80 & 60 & 50 & 80 & 60 & 50 \\
\hline$\rho_{m}$ & $\mathrm{~kg} \cdot \mathrm{m}^{-3}$ & 39.9 & 53.1 & 63.8 & 40.1 & 53.4 & 64.1 \\
\hline$w_{m} \pm S D$ & $\%$ & \multicolumn{3}{|c|}{$2.12 \pm 0.268^{\mathrm{a}}$} & \multicolumn{3}{|c|}{$2.22 \pm 0.308^{\mathrm{a}}$} \\
\hline$t_{m} \pm S D$ & ${ }^{\circ} \mathrm{C}$ & $22.0 \pm 4.77$ & $25.6 \pm 0.85$ & $\begin{array}{c}23.9 \pm \\
3.75\end{array}$ & $22.0 \pm 5.15$ & $25.8 \pm 0.83$ & $22.0 \pm 6.25$ \\
\hline$t_{e} \pm S D$ & ${ }^{\circ} \mathrm{C}$ & $21.6 \pm 4.85$ & $25.6 \pm 1.26$ & $23.6 \pm 3.8$ & $21.7 \pm 5.24$ & $25.0 \pm 0.89$ & $23.8 \pm 5.4$ \\
\hline$\lambda_{m} \pm S D$ & $\mathrm{~W} \cdot \mathrm{m}^{-1} \cdot \mathrm{K}^{-1}$ & $\begin{array}{c}0.041 \pm \\
0.001^{\mathrm{a}, \mathrm{d}, \mathrm{e}}\end{array}$ & $\begin{array}{c}0.044 \pm \\
0.001^{\mathrm{b}, \mathrm{c}, \mathrm{d}, \mathrm{e}, \mathrm{f}}\end{array}$ & $\begin{array}{l}0.046 \pm \\
0.001^{\mathrm{b}, \mathrm{c}, \mathrm{f}}\end{array}$ & $\begin{array}{l}0.041 \pm \\
0.001^{\mathrm{a}, \mathrm{b}, \mathrm{d}, \mathrm{e}}\end{array}$ & $\begin{array}{l}0.043 \pm \\
0.0004^{\mathrm{a}, \mathrm{b}, \mathrm{d}, \mathrm{e}, \mathrm{f}}\end{array}$ & $\begin{array}{l}0.045 \pm \\
0.001^{\mathrm{b}, \mathrm{c}, \mathrm{e}, \mathrm{f}}\end{array}$ \\
\hline$\lambda$ & $\mathrm{W} \cdot \mathrm{m}^{-1} \cdot \mathrm{K}^{-1}$ & 0.04 & \multicolumn{2}{|c|}{---} & 0.04 & \multicolumn{2}{|c|}{---} \\
\hline
\end{tabular}

\section{Conclusions}

1. Properly installed and treated straw boards Solomit did not change the thermal insulation properties even after a period twice longer than the life expectancy specified by the manufacturer.

2. The thermal conductivity of the straw boards Solomit depends on the orientation of the stalk material. If the heat flux is directed in the direction perpendicular to the blades of the thermal conductivity it is lower than that in the direction along the stalks.

3. Crushing of the stalk structure before the production of building materials of vegetable origin enables the subsequent production of panels with constant thermal insulation properties.

4. By deformation of the thermal insulating material not only its density is changed, but also the thermal conductivity.

\section{References}

1. Jeřábek E. et al. Zemědělské stroje a traktory - Výrobní program 1961-1962 (Agricultural machinery and tractors - Production program). Prague: Státní zemědělské nakladatelství v Praze, 1961, 395 p. (In Czech)

2. Chybík J. Přírodní stavební materiály (Natural building materials). Prague: Grada Publishing a.s., 2009. 272 p. (In Czech).

3. Knap J. Výsledky z ověrování solomitu při stavbě stájí pro prasata (The results of the verification Solomit used for the construction of stables for pigs). Živočišná výroba (Animal Science), vol. 7, 1962, pp. 107-126. (In Czech).

4. United Nations Centre for Human Settlements. National design handbook prototype on passive solar hearing and natural cooling of buildings. Nairobi: United Nations Centre for Human Settlements (Habitat), 1990. 210 p.

5. Dickson R. Addicted To Architecture. Kent Town: Wakefield Press, 2010, 246 p.

6. Visockis E., Pleiksnis S., Gross U., Noviks G. Use of Tree Leaves-Lime Mixture for Building Insulation. Proceedings of International conference "Engineering for Rural Development", May 25-27, 2016, Jelgava. Latvia, pp. 86-90.

7. Dane J. H., and Topp G. C et al. Methods of Soil Analysis: Part 4 Physical Methods. Madison: Soil Science Society of Amerika. 2002. 866 p. 